\title{
AC DRIVE SYSTEMS USING REDUCED FOUR-LEG CONVERTER SUPPLYING INDEPENDENTLY TWO INDUCTION MACHINES
}

\author{
Euzeli C. dos Santos Jr. ${ }^{1,2}$, Cursino B. Jacobina ${ }^{1}$, Maurício B. R. Correa ${ }^{1}$ \\ ${ }^{1}$ Laboratório de Eletrônica Industrial e Acionamento de Máquinas \\ Departamento de Engenharia Elétrica, Universidade Federal de Campina Grande \\ Caixa Postal 10105; 58109-970 Campina Grande, PB; Brasil \\ Fax: ++55(83)3310-1015; Fone: +55(83)3310-1136 \\ ${ }^{2}$ Unidade de Ensino Descentralizada - UNED Cajazeiras \\ Centro Federal de Educação Tecnológica da Paraíba - CEFET PB \\ e-mail: [euzeli,jacobina,mbrcorrea]@dee.ufcg.edu.br
}

\begin{abstract}
This paper presents six reduced switch count ac drive systems. These configurations have been conceived to operate with a four-phase and a three-phase or with a four-phase and a two-phase induction machines in a series-connected scheme. The overall control of the drive system is presented, including the pulse width modulation techniques. The proposed two-motor drive systems are seen as a potentially feasible industrial solution for applications that demand one high-power and one low-power machine. Experimental results are presented.
\end{abstract}

Keywords - Induction motor, Motor drive system, Reduced components, Series connected machines.

\section{INTRODUCTION}

A standard ac machine drive system is constituted by an input rectifier, dc-bus capacitors, a voltage source inverter, an electrical machine and a microcomputer based control system. In industrial applications where it is required to drive multiple electrical machines, the direct solution consists in replicating such standard configuration. One of the first alternatives for reducing costs in this case is to use a common dc-bus for all machine drive systems installed in the shop-floor. A second alternative to further reduce the installation costs is to use converter topologies with a minimized number of power switching devices [1] - [12].

A different concept, that is an interesting approach to compose the reduced switch count ac drive systems, is based on utilization of multi-phase machines, because it utilizes a single inverter to supply all the motors. The idea stems from the fact that any $n$-phase ac machine requires only two currents ( $d q$ currents) for independent flux and torque control. Thus, in a multi-phase machine there are additional degrees of freedom, which can be used to control other machines [13], [14], [15], [19]. It has been shown that, by connecting multi-phase stator windings in series with an appropriate phase connection, it becomes possible to control independently all machines with the supply coming from a single multi-phase inverter.

Manuscript received on August 28, 2006. First revision on November 16, 2006. Second revision on January 23, 2007. Rocommended by the Editor Richard M. Stephan.
This paper presents six ac drive systems, comprising one four-phase and one three-phase or two-phase induction machines in a series-connected scheme. First topology, named Configuration $A$, the phase 3 of the three-phase machine is connected to the dc-bus mid-point [see Fig. 1]. Other five possible configurations are shown in Fig. 2, in these topologies one four-phase machine is connected with a three-phase machine [see Fig. 2 (a)], or one four-phase machine is connected with a two-phase machine [see Fig. 2 (b) - Fig. 2 (e)]. This paper will study in details one of the proposed configurations (Fig. 1) and the other ones can be derived directly from Configuration $A$. The Configuration $A$ has been chosen due to it has the best ratings (such as voltage capability and capacitor current) in comparison with other ones. Moreover the three-phase machine is more popular than the two-phase machine.

Although a single supply source is used, it is shown that a truly independent and decoupled control of the two machines is obtained. The two-motor drive system of the proposed structure is seen as a potentially feasible industrial solution for applications requiring one high-power (four-phase machine) and one low-power (three-phase or two-phase machine) machine. For example, such configurations can be useful for supplying traction and compression machines in automotive applications [16], [17].

\section{MACHINE DYNAMIC MODEL}

The machines used in this work are a four-phase symmetric machine and a typical three-phase (or two-phase) machine. The four-phase machine is composed by four windings $\pi / 2$ rad away from each other. Adopting a stationary reference frame, the mathematical model that describes the dynamic behavior of the four-phase machine is given by (1)-(7) while for the three-phase machine the model is given by (1)-(4) and (7) since the homopolar current $(o)$ is null.

$$
\begin{gathered}
v_{s d q}=r_{s} i_{s d q}+\frac{d}{d t} \phi_{s d q} \\
v_{r d q}=r_{r} i_{r d q}+\frac{d}{d t} \phi_{r d q}-j \omega_{r} \phi_{r d q} \\
\phi_{s d q}=l_{s} i_{s d q}+l_{s r} i_{r d q} \\
\phi_{r d q}=l_{s r} i_{s d q}+l_{r} i_{r d q} \\
v_{s o}=r_{s} i_{s o}+l_{l s} \frac{d}{d t} i_{s o}
\end{gathered}
$$




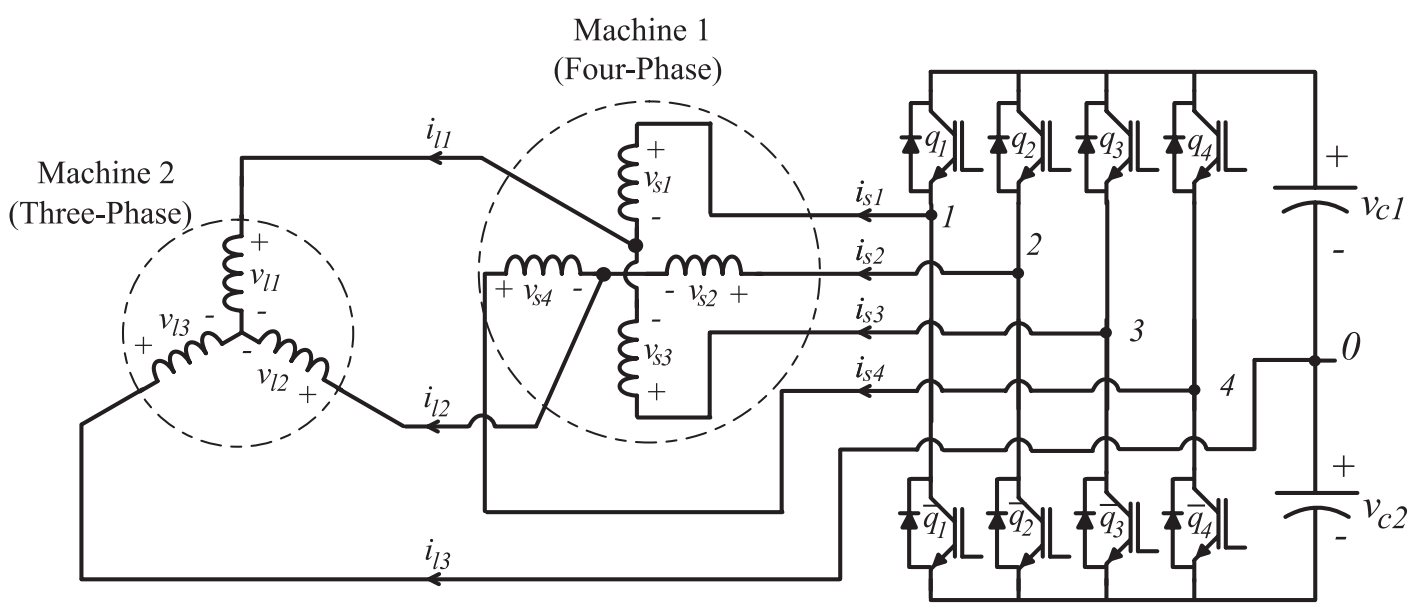

Fig. 1. Proposed ac drive system using reduced four-leg inverter supplying independently two machines - Configuration $A$.

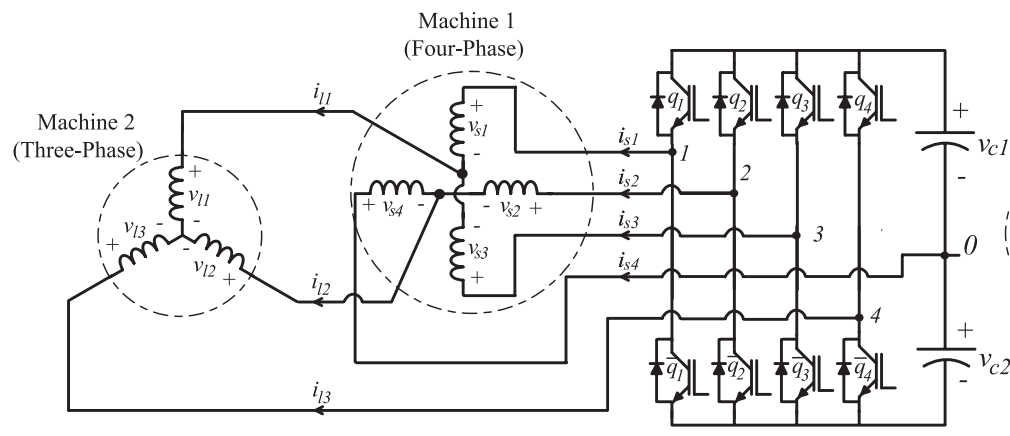

(a)

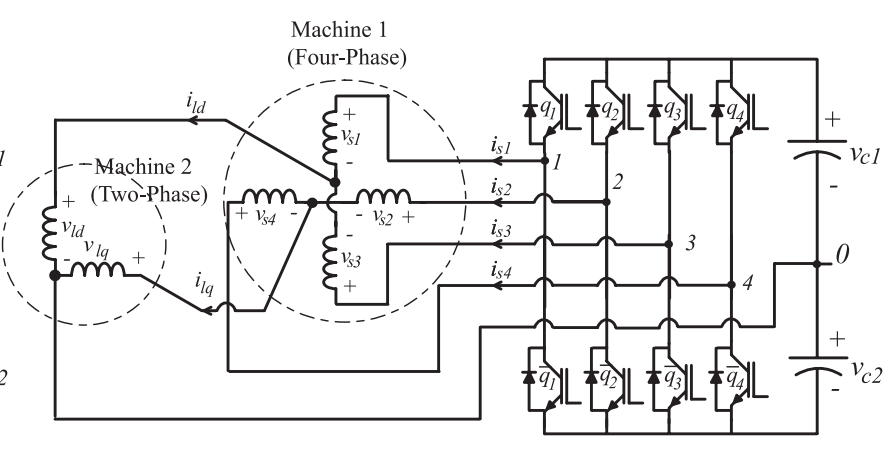

(b)

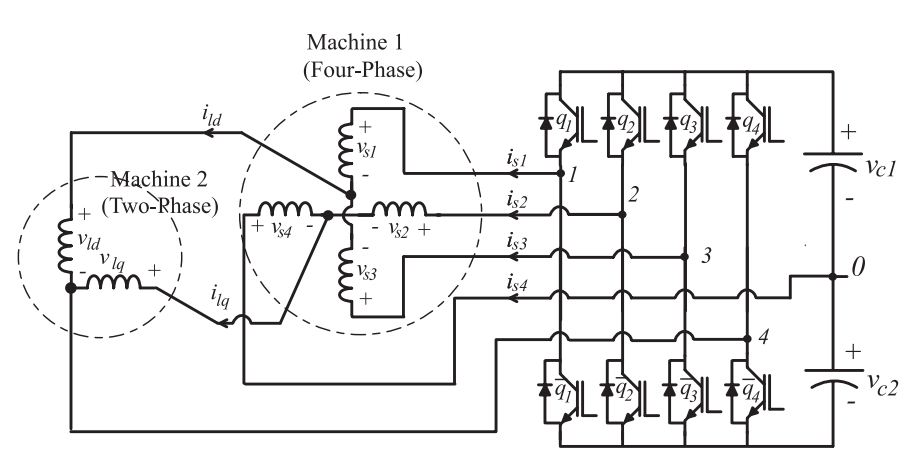

(c)

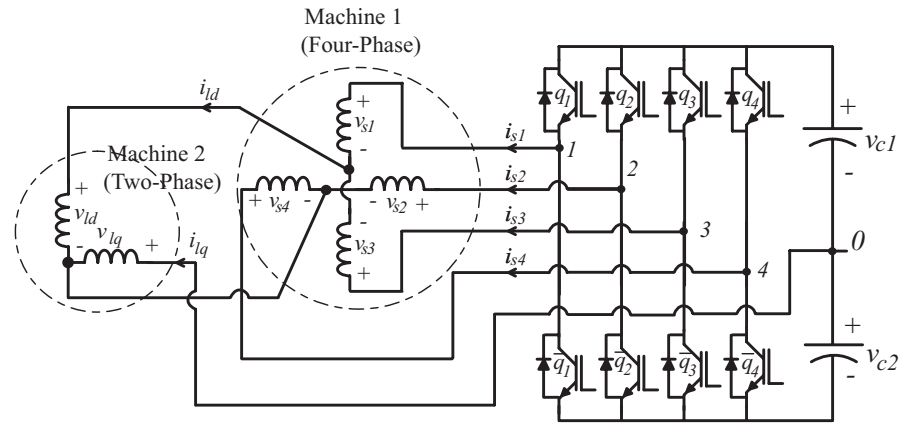

(d)

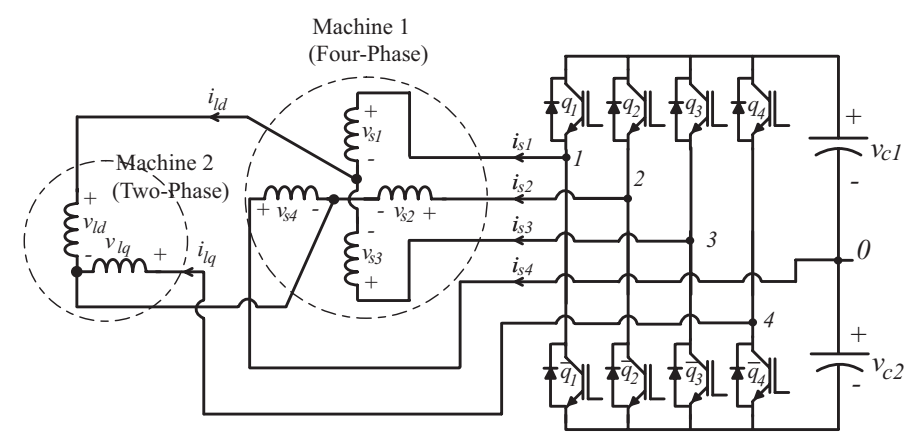

(e)

Fig. 2. Other possible ac drive systems using reduced four-leg inverter supplying independently two machines: (a) Configuration $B$, (b) Configuration $C$, (c) Configuration $D$, (d) Configuration $E$ and (e) Configuration $F$.

82

Eletrônica de Potência, vol. 12, nº 1, Março de 2007 


$$
\begin{gathered}
v_{r o}=r_{r} i_{r o}+l_{l r} \frac{d}{d t} i_{r o} \\
T_{e}=P l_{s r}\left(i_{s q} i_{r d}-i_{s d} i_{r q}\right) .
\end{gathered}
$$

Where

$$
v_{s d q}=v_{s d}+j v_{s q}, \quad i_{s d q}=i_{s d}+j i_{s q}
$$

$\phi_{s d q}=\phi_{s d}+j \phi_{s q}$ are the voltage, current, and flux $d q$ vectors of the stator, respectively; $v_{s h o}=v_{s h}+j v_{s o}, i_{s h o}=i_{s h}+j i_{s o}$ and $\phi_{s h o}=\phi_{s h}+j \phi_{s o}$ are voltage, current and flux ho homopolar no-torque vectors of the stator, respectively (the equivalent rotor variables are obtained by replacing the subscript $s$ by $r$ ); $T_{e}$ is the electromagnetic torque; $\omega_{r}$ is the angular frequency of the rotor; $r_{s}$ and $r_{r}$ are the stator and rotor resistances; $l_{s}, l_{l s}, l_{r}$ and $l_{l r}$ are the self and leakage inductance of the stator and rotor, respectively; $l_{s r}$ is the mutual inductance and $P$ is the number of pole pairs.

The $d q h o$ stator variables of the four-phase machine can be determined from the 1234 variables, similarly for the three-phase machine $d q o$ stator variables can be determined from the 123 variables by using the transformation given, respectively by

$$
\begin{gathered}
w_{s 1234}=A_{4} w_{s d q h o} \\
w_{s 123}=A_{3} w_{s d q o}
\end{gathered}
$$

with $w_{s 1234}=\left[w_{s 1}, w_{s 2}, w_{s 3}, w_{s 4}\right]^{T}, w_{s d q h o}=\left[w_{s d}, w_{s q}, w_{s h}\right.$, $\left.w_{s o}\right]^{T}, w_{s 123}=\left[w_{s 1}, w_{s 2}, w_{s 3}\right]^{T}$ and $w_{s d q o}=\left[w_{s d}, w_{s q}\right.$, $\left.w_{s o}\right]^{T}, A_{4}$ and $A_{3}$ can be obtained from [22], [23], [24] and [3], respectively.

Vectors $w_{s 1234}, w_{\text {sdqho }}, w_{s 123}$ and $w_{\text {sdqo }}$ can be voltage, or current, or flux vectors.

The two-phase equivalent $d q$ motor model is also given by (1) - (4) and (7).

\section{SYSTEM MODEL}

The configuration shown in Fig. 1 comprises four-leg (eight switches), dc-bus capacitors, and one three-phase, and one four-phase machines. The converter is composed by switches $q_{1}, \bar{q}_{1}, q_{2}, \bar{q}_{2}, q_{3}, \bar{q}_{3}, q_{4}$ and $\bar{q}_{4}$. The switchpairs $\left(q_{1}, \bar{q}_{1}\right), \quad\left(q_{2}, \bar{q}_{2}\right), \quad\left(q_{3}, \bar{q}_{3}\right)$ and $\left(q_{4}, \bar{q}_{4}\right)$ are complementary. The conduction state of all switches is represented by a homonymous binary variable $q_{1}, q_{2}, q_{3}$, and $q_{4}$, where $q=1$ indicates a closed switch while $q=0$ indicates an open one.

The converter pole voltages can be written as a function of phase voltage of the three-phase and four-phase machines, or as a function of conduction state of the switches, as follow

$$
\begin{aligned}
& v_{10}=v_{s 1}+v_{l 13}=q_{1} v_{c 1}-\left(1-q_{1}\right) v_{c 2} \\
& v_{20}=v_{s 2}+v_{l 23}=q_{2} v_{c 1}-\left(1-q_{2}\right) v_{c 2} \\
& v_{30}=v_{s 3}+v_{l 13}=q_{3} v_{c 1}-\left(1-q_{3}\right) v_{c 2} \\
& v_{40}=v_{s 4}+v_{l 23}=q_{4} v_{c 1}-\left(1-q_{4}\right) v_{c 2}
\end{aligned}
$$

where $v_{s i}(i=1$ to 4$)$ and $v_{l j}(j=1$ to 3$)$ are phase voltages of the four-phase and the three-phase machines, respectively; $v_{l 13}=v_{l 1}-v_{l 3}$ and $v_{l 23}=v_{l 2}-v_{l 3}$.

Considering (10) - (13), the phase voltage of the fourphase machine, can be obtained as follows

$$
\begin{gathered}
v_{s 1}=v_{10}+v_{l 31} \\
v_{s 2}=v_{20}+v_{l 32} \\
v_{s 3}=v_{30}+v_{l 31} \\
v_{s 4}=v_{40}+v_{l 32} .
\end{gathered}
$$

Note that the phase voltages of the four-phase machine depend on the $v_{l 1}, v_{l 2}, v_{l 3}$ (three-phase machine voltages), due to the series-connected machines scheme. Summing (14) - (17) can be obtained

$$
\sum_{j=1}^{4} v_{s j}=\sum_{j=1}^{4} v_{s j 0}+2 v_{l 31}+2 v_{l 32}
$$

By assuming $v_{l 1}+v_{l 2}+v_{l 3}=0$, (18) can be write as follow

$$
\sum_{j=1}^{4} v_{s j}=\sum_{j=1}^{4} v_{s j 0}+6 v_{l 3} \Rightarrow v_{l 3}=\frac{1}{6}\left[\sum_{j=1}^{4} v_{s j}+\sum_{j=1}^{4} v_{s j 0}\right]
$$

writing the homopolar voltage as a function of phase voltages [using (8)], i.e., $v_{s o}=\frac{1}{2} \sum_{j=1}^{4} v_{s j}$ (19) becomes

$$
v_{l 3}=-\frac{\left(v_{10}+v_{20}+v_{30}+v_{40}\right)}{6}+\frac{v_{s o}}{3}
$$

the other three-phase machine voltages can be obtained substituting (20) in (18) and following the same steps as done for $v_{l 3}$

$$
\begin{gathered}
v_{l 1}=\frac{\left(v_{10}+v_{30}\right)}{3}-\frac{\left(v_{20}+v_{40}\right)}{6}-\frac{v_{s h}}{2}-\frac{v_{s o}}{6} \\
v_{l 2}=-\frac{\left(v_{10}+v_{30}\right)}{6}+\frac{\left(v_{20}+v_{40}\right)}{3}+\frac{v_{s h}}{2}-\frac{v_{s o}}{6}
\end{gathered}
$$

Note that for the three-phase machine, the phase voltages depend on the homopolar voltages of the four-phase machine, i.e., as expected there is a coupling between both machines, as shown in (14) - (17) and (20) - (22).

In spite of the phase voltages of both machines have connection on the each other, will be shown that the $d q$ voltage of the four-phase machine is independent. This is important issue because the torque of the machines is dependent on the $d q$ variables [see (7)].

Next, the $d q$ and homopolar variables will be obtained for both machines. By using (14) - (17) and (8) the $d q$ ho voltages of the four-phase machine are given by

$$
\begin{gathered}
v_{s d}=\frac{\sqrt{2}}{2}\left(v_{10}-v_{30}\right) \\
v_{s q}=\frac{\sqrt{2}}{2}\left(v_{20}-v_{40}\right) \\
v_{s h}=\frac{1}{2}\left(v_{10}-v_{20}+v_{30}-v_{40}\right)+v_{l 21} \\
v_{s o}=\frac{1}{2} \sum_{j=1}^{4} v_{j 0}+3 v_{l 3}
\end{gathered}
$$


where $v_{l 21}=v_{l 2}-v_{l 1}$.

By using (20) - (22) and (9) the $d q$ voltages of the threephase machine are given by

$$
\begin{gathered}
v_{l d}=\sqrt{\frac{2}{3}}\left[\left(\frac{v_{10}+v_{30}}{2}\right)-\left(\frac{v_{20}+v_{40}}{4}\right)-\frac{3 v_{s h}}{4}-\frac{v_{s o}}{4}\right] \\
v_{l q}=\frac{1}{\sqrt{2}}\left[\left(\frac{v_{20}+v_{40}}{2}\right)+\frac{v_{s h}}{2}-\frac{v_{s o}}{2}\right] .
\end{gathered}
$$

For the four-phase machine only variables ho depend on $v_{l 1}, v_{l 2}, v_{l 3}$, while variables $d q$ can be obtained independently. Note that, for the three-phase machine, the $d q$ model is coupled with voltages of the four-phase machine. To make explicit that the ho voltages of the four-phase machine depend on the phase voltages of the three-phase machine and the $d q$ voltages of the three-phase machine depend on the ho voltage of the four-phase machine, new variables $h^{\prime} o^{\prime}$ and $d^{\prime} q^{\prime}$ were introduced, such $v_{s h}^{\prime}=v_{s h}+v_{l 12}, \quad v_{s o}^{\prime}=v_{s o}-3 v_{l 3}, \quad v_{l d}^{\prime}=v_{l d}+$ $3 / 4 v_{s h}+1 / 4 v_{s o}$ and $v_{l q}^{\prime}=v_{l q}-1 / 2 v_{s h}+1 / 2 v_{s o}$. In this case, the terms depending on three-phase machine voltages are incorporated into the stator ho model (5), which becomes

$$
\begin{gathered}
v_{s h o}^{\prime}=r_{s} i_{s h o}+l_{l s} \frac{d}{d t} i_{s h o}+v_{l s} \\
v_{l d q}^{\prime}=r_{s} i_{l d q}+\frac{d}{d t} \lambda_{l d q}+e_{s l}
\end{gathered}
$$

where

$$
\begin{gathered}
v_{l s}=v_{l s h}+j v_{l s o}=v_{l 12}-j 3 v_{l 3} \\
e_{s l}=e_{l s h}+j e_{l s o} \\
=3 / 4 v_{s h}+1 / 4 v_{s o}+j\left(-1 / 2 v_{s h}+1 / 2 v_{s o}\right)
\end{gathered}
$$

The models for topologies shown in Fig. 2(a) - Fig. 2(e) can be derived as done for Configuration $A$.

The motor phase current (four-phase machine) $i_{s j}(j=1$ to 4) are given by

$$
i_{s j}=i_{s d q j}+i_{s h o j} ; j=1 \text { to } 4
$$

where $i_{s d q 1}=-i_{s d q 3}=i_{s d} / \sqrt{2}$ and $i_{s d q 2}=-i_{s d q 4}=i_{s q} / \sqrt{2}$ [obtained from (8) with $i_{s h}=i_{s o}=0$ ]; also $i_{\text {sho } 1}=i_{\text {sho } 3}=i_{\text {sh }} / 2+_{\text {so }} / 2$ and $i_{\text {sho } 2}=-i_{\text {sho } 4}=-i_{\text {sh }} / 2$ $+i_{s o} / 2$ [obtained from (8) with $i_{s d}=i_{s q}=0$ ].

Since $i_{s 1}+i_{s 3}=i_{l 1}$ and $i_{s 2}+i_{s 4}=i_{l 2}$ it follows that

$$
i_{l 1}=i_{s h}+i_{s o} ; \quad i_{l 2}=-i_{s h}+i_{s o}
$$

or

$$
i_{s h}=\frac{i_{l 1}-i_{l 2}}{2} ; \quad i_{s o}=\frac{i_{l 1}+i_{l 2}}{2}
$$

By using (36) and the previous expression for $i_{s d q 1}$ to $i_{s d q 4}$ and $i_{\text {sho } 1}$ to $i_{\text {sho } 4}$, (34) becomes

$$
\begin{gathered}
i_{s 1}=i_{s d} / \sqrt{2}+i_{l 1} / 2 \\
i_{s 2}=i_{s q} / \sqrt{2}+i_{l 2} / 2 \\
i_{s 3}=-i_{s d} / \sqrt{2}+i_{l 1} / 2
\end{gathered}
$$

$$
i_{s 4}=-i_{s q} / \sqrt{2}+i_{l 2} / 2
$$

As a result of such analysis, model diagram for the $d q$ and ho variables can be defined as depicted in Fig. 3 (a). Note that these two models are decoupled and only the ho model is coupled with voltages of the three-phase machine. While the model diagram for the $d q$ variables, for the three-phase machine, can be defined as depicted in Fig. 3 (b).

The complete model for other configurations (see Fig. 2) can be obtained directly as done for Configuration $A$.

\section{PWM CONTROL}

From now on the desired machine phase voltages are specified by $v_{s 1}^{*}, v_{s 2}^{*}, v_{s 3}^{*}$ and $v_{s 4}^{*}$ (four-phase machine), and $v_{l 1}^{*}, v_{l 2}^{*}$ and $v_{l 3}^{*}$ (three-phase machine). Therefore, from (10) - (13) the reference mid-point voltages can be expressed as

$$
\begin{gathered}
v_{10}^{*}=v_{s 1}^{*}+v_{l 1}^{*}-v_{l 3}^{*} \\
v_{20}^{*}=v_{s 2}^{*}+v_{l 2}^{*}-v_{l 3}^{*} \\
v_{30}^{*}=v_{s 3}^{*}+v_{l 1}^{*}-v_{l 3}^{*} \\
v_{40}^{*}=v_{s 4}^{*}+v_{l 2}^{*}-v_{l 3}^{*}
\end{gathered}
$$

Writing (41) - (44) in terms of $d q h o$ voltages (for the fourphase machine) and in terms of $d q$ voltages (for the threephase machine), the reference mid-point voltages can be expressed as

$$
\begin{gathered}
v_{10}^{*}=\frac{\sqrt{2}}{2} v_{s d}^{*}+\frac{\sqrt{6}}{2} v_{l d}^{\prime *}+\frac{\sqrt{2}}{2} v_{l q}^{\prime *} \\
v_{20}^{*}=\frac{\sqrt{2}}{2} v_{s q}^{*}+\sqrt{2} v_{l q}^{* *} \\
v_{30}^{*}=-\frac{\sqrt{2}}{2} v_{s d}^{*}+\frac{\sqrt{6}}{2} v_{l d}^{\prime *}+\frac{\sqrt{2}}{2} v_{l q}^{\prime *} \\
v_{40}^{*}=-\frac{\sqrt{2}}{2} v_{s q}^{*}+\sqrt{2} v_{l q}^{*}
\end{gathered}
$$

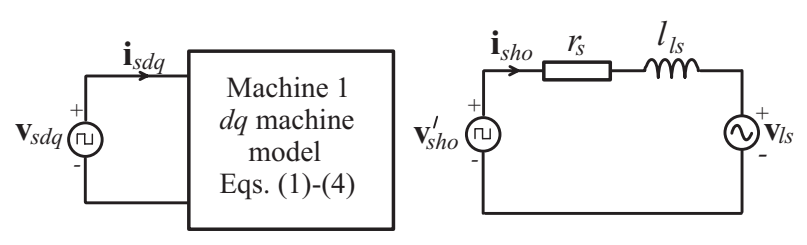

(a)

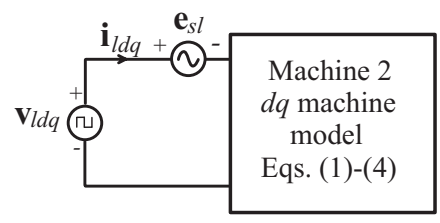

(b)

Fig. 3. Diagram models: (a) Four-phase machine drive system. (b) Three-phase machine drive system. 
where $v_{l d}^{\prime *}=v_{l d}^{*}+v_{s h o d}$ and $v_{l q}^{\prime *}=v_{l q}^{*}+v_{s h o q}$ with

$$
v_{\text {shod }}=-\frac{3}{4} v_{s h}-\frac{1}{4} v_{s o} \text { and } v_{\text {shoq }}=-\frac{1}{2} v_{s o}
$$

Based on (5) and (36) the homopolar voltages ( $v_{\text {shod }}$ and $v_{\text {shoq }}$ ) can be obtained as a function of three-phase machine current, as follow

$$
\begin{aligned}
& v_{\text {shod }}=\frac{r_{s}}{2}\left(\frac{i_{l 2}}{2}-i_{l 1}\right)+\frac{l_{l s}}{2} \frac{d}{d t}\left(\frac{i_{l 2}}{2}-i_{l 1}\right) \\
& v_{\text {shoq }}=-\frac{r_{s}}{4}\left(i_{l 1}+i_{l 2}\right)-\frac{l_{l s}}{4} \frac{d}{d t}\left(i_{l 1}+i_{l 2}\right)
\end{aligned}
$$

The amplitude of $v_{\text {shod }}$ and $v_{\text {shoq }}$ should be small since the homopolar impedance is small.

In the PWM control strategy is more interesting to use (45) - (48) than (41) - (44) because the output torque control defines the $d q$ voltages for both machines, as will be shown in the Section V (Control Strategy).

Once the mid-point voltage $\left(v_{10}^{*}\right.$ to $\left.v_{40}^{*}\right)$ have been determined, pulse widths $\tau_{1}$ to $\tau_{4}$ are calculated by using

$$
\tau_{j}=\left(\frac{T}{2}+\frac{T}{E}\right) v_{j 0}^{*} \quad \text { for } \quad j=1 \text { to } 4
$$

where $E=v_{c}^{*}$ (total dc-bus voltage), $T$ is the switching period and gating signals ( $\tau_{1}$ to $\tau_{4}$ ) are generated with programmable timers. Alternatively, gating signals can be generated comparing modulating reference signals $v_{10}^{*}$ to $v_{40}^{*}$ with a high frequency triangular carrier signal.

On the other hand, to eliminate the error due to the capacitor unbalance resultant from the capacitor midpoint connection, the expression (52) is no longer valid, because this one uses the reference value of the dc-bus voltage. To compensate the capacitor unbalanced, pulse widths must be computed by using (53). The new expression for $\tau_{1}$ to $\tau_{4}$ is given by

$$
\tau_{j}=\left(v_{j 0}^{*}+v_{c 2}\right) \frac{T}{v_{c 1}+v_{c 2}} \text { for } j=1 \text { to } 4
$$

Note that it is necessary to measure $v_{c 1}$ and $v_{c 2}$. This expression was obtained in [21].

The PWM control strategy for configurations shown in Fig. 2 can be obtained as done for Configuration $A$.

\section{CONTROL STRATEGY}

The $d q$ variables of the four-phase and three-phase machine can be controlled independently. The torque control law for both machines, which includes a flux control law, can be achieved by controlling the $d q$ currents (e.g., field oriented or the $d q$ volts/hertz control). The homopolar variables of the four-phase machine are defined by the control law of the three-phase machine.

\section{A. Control Block Diagram}

Fig. 4 shows the control block diagram for Configuration

$A$. The torque control law defines the voltages $v_{s d q}^{*}$ (fourphase machine) and $v_{l d q}^{*}$ (three-phase machine).

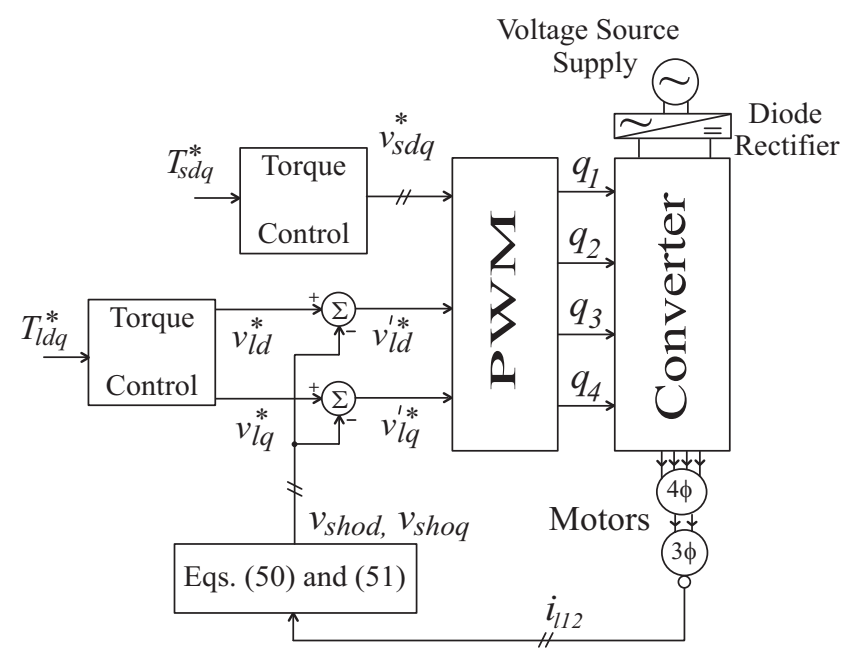

Fig. 4. Control system block diagram for Configuration $A$.

If the torque control of three-phase machine is implemented in open loop (for example, volts/hertz control) it is necessary to determine $v_{\text {shod }}$ and $v_{\text {shoq }}$; in this case $v_{\text {shod }}$ and $v_{\text {shoq }}$ can be calculated by using $i_{l 1}$ and $i_{l 2}$ as shown in (50) and (51).

When a closed loop torque control or a closed loop current control are employed it is not necessary to determine $v_{\text {shod }}$ and $v_{\text {shoq }}$, the controller supplies indirectly these voltages.

The PWM strategy is implemented by using the method introduced in Section IV. The capacitor voltage is a function of the input grid voltage, since has been used a diode rectifier.

Similar control block diagram can be obtained for other configurations (see Fig. 2).

\section{B. Voltage Analysis}

The voltage limits can be determined by considering that all voltages are purely sinusoidal. Since $v_{j 0}^{*} \leq E / 2(j=1$ to $4)$, the dc-bus voltage necessary for each configuration is determined as following

$$
E \geq 2\left(V_{s d q}+V_{s h o}+\sqrt{2} V_{l d q}\right)
$$

where $V_{s d q}, V_{l d q}$ are the amplitude of the $d q$ voltages for the four-phase and three-phase machines, respectively; $V_{\text {sho }}$ is a reduced voltage associated to the drop voltage across the ho impedance.

\section{Capacitor Current}

The average value (over the switching period $T$ ) of the current flowing though the shared-leg and the upper side capacitor $\left(i_{\text {cup }}\right)$ of the capacitor bank is an important issue for the proposed configurations. This current is given by

$$
\bar{i}_{\text {cup }}=\frac{1}{2}\left(-i_{l 3}\right)
$$


Then, the capacitor currents reduce with decreasing of the three-phase current.

\section{EXPERIMENTAL RESULTS}

The topology presented in Fig. 1 has been implemented experimentally in the laboratory. All experimental results shown is referent to Configuration $A$.

The set-up (Fig. 5) used in the experimental tests is based on a microcomputer (PC-Pentium) equipped with appropriate plug-in boards and sensors.

Fig. 6 shows a transient created by increase of the amplitude of the reference $d q$ current of the three-phase machine. As expected the independent control was obtained.

Fig. 7 and Fig. 8 present experimental results employing the system shown in Fig. 1. These results presents the phase currents $\left(i_{s 1}, i_{s 2}, i_{s 3}, i_{s 4}\right.$ - Four-phase machine) [see Fig. 7(a)], $d q$ currents $\left(i_{s d}, i_{s q}\right)$ [see Fig. 7(b)]; phase currents

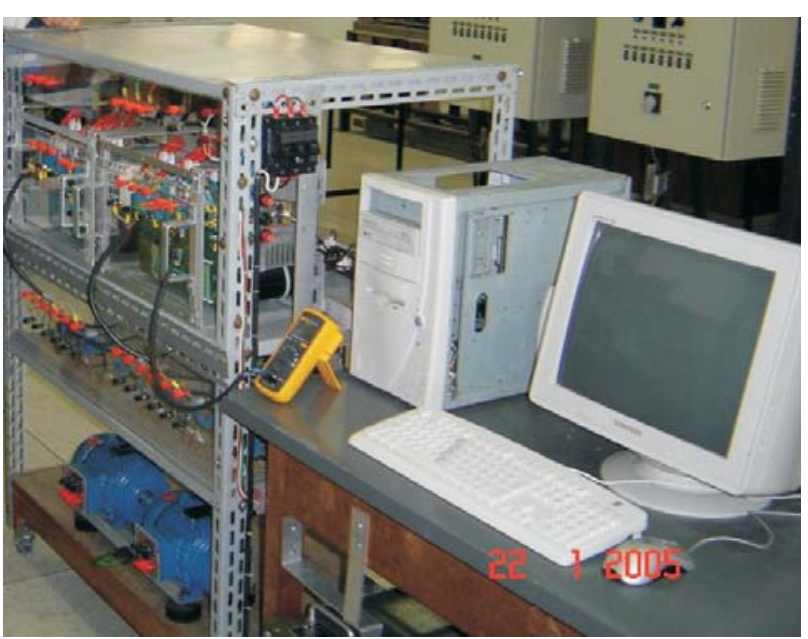

Fig 5. Experimental set-up.
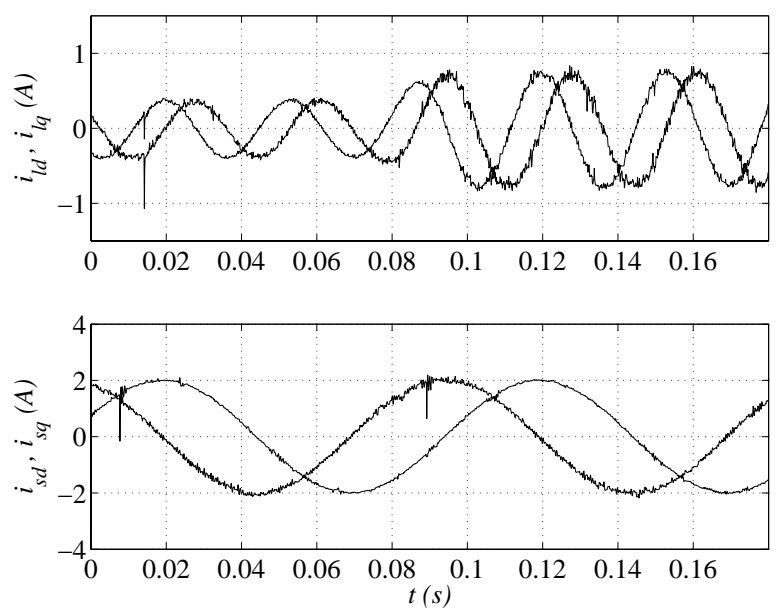

Fig. 6. Experimental results with transient. $d q$ currents of the threephase machine (top). $d q$ currents of the four-phase machine (bottom).
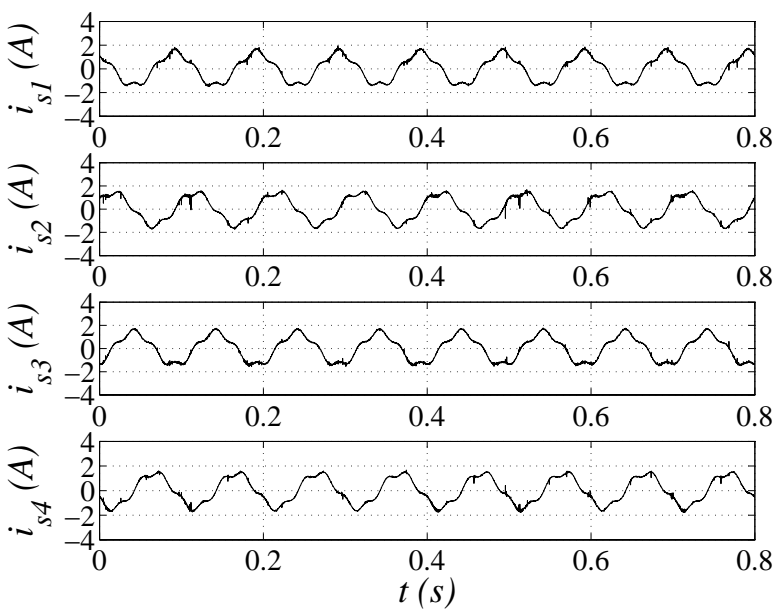

(a)

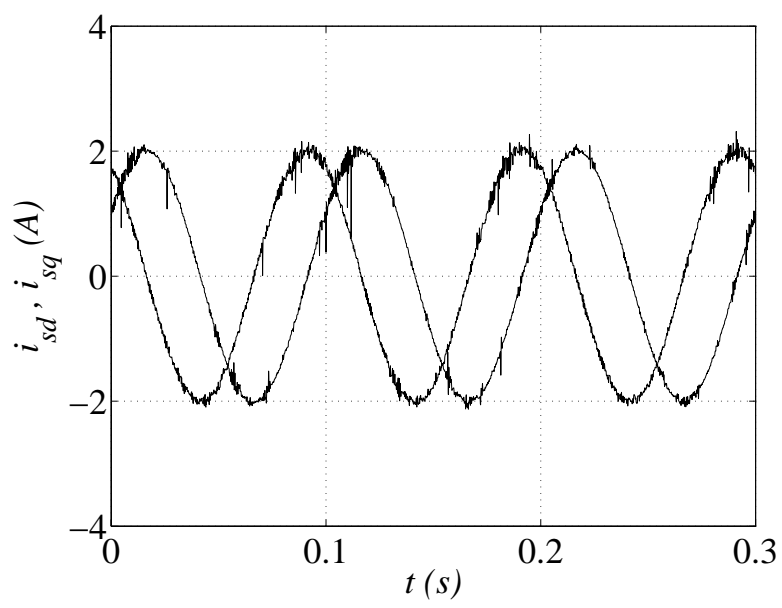

(b)

Fig. 7. Experimental results of four-phase machine operating at 10Hz: (a) phase currents and (b) $d q$ currents.

$\left(i_{l 1}, i_{l 2}, i_{l 3}\right.$ - Three-phase machine) [see Fig. 8(a)], and $d q$ currents $\left(i_{l d}, i_{l q}\right.$ - Three-phase machine) [see Fig. 8(b)]. It is worthwhile to note that $d q$ currents are balanced, for both machines, which means that an effective torque control can be achieved despite of distorted phase currents in four-phase machine.

\section{CONCLUSIONS}

This paper has presented six reduced switch count ac drive systems. Full details of Configuration $A$ have been presented; the other configurations (Fig. 2) can be derived directly from Configuration $A$. The configurations were conceived to operate with combining a four-phase and a three-phase (or two-phase) induction machines in a seriesconnected scheme. 


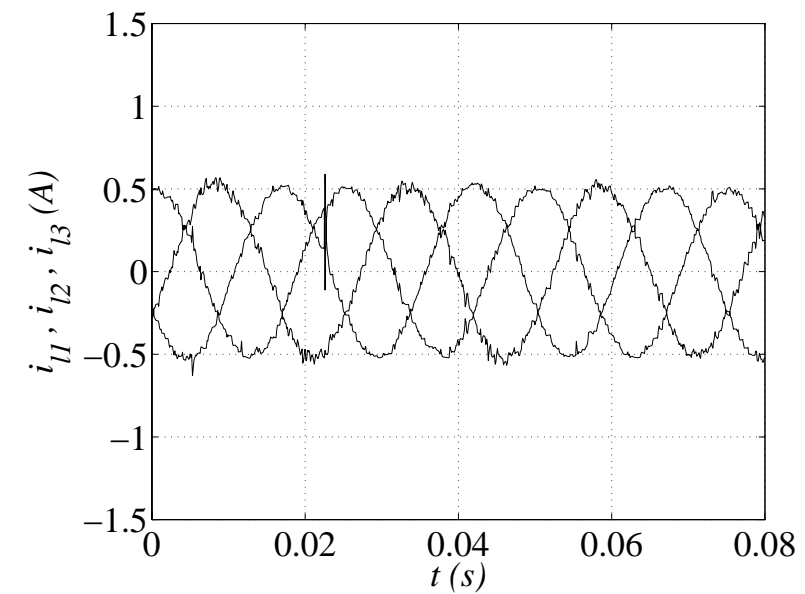

(a)

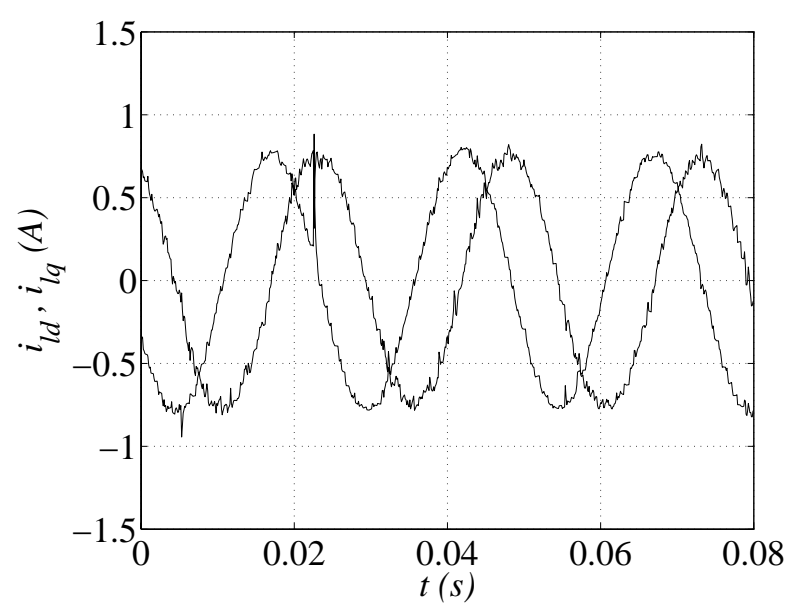

(b)

Fig. 8. Experimental results with transient. $d q$ currents of the threephase machine (top). $d q$ currents of the four-phase machine (bottom).

Independent control for both machines can be achieved. The results have demonstrated the feasibility of the Configuration $A$.

These drive systems are very suitable for applications where the size of the system is a critical factor. In fact, each configuration is an optimized monolithic system constituted by the converter and dedicated motors.

\section{ACKNOWLEDGEMENT}

Authors would like to thank the financial support provided by the Conselho Nacional de Desenvolvimento Científico e Tecnológico (CNPq) and the Coordenação de Aperfeiçoamento de Pessoal de Nível Superior (CAPES) of Brazil.

\section{REFERENCES}

[1] H. W. Van der Broeck, J. D. Van Wyk. "A comparative investigation of a three-phase induction machine drive with a component minimized voltage-fed inverter under different control options", IEEE Transactions on Industry Applications, vol. 20, no. 2, pp. 309-320, March/April 1984.

[2] F. Blaabjerg, S. Freysson, H. H. Hansen, and S. Hansen. "Comparison of a space-vector modulation strategy for a three phase standard and a component minimized voltage source inverter", in Proc. of EPE, pp. 18061813, 1995.

[3] E. C. dos Santos Jr, C. B. Jacobina, M. B. R. Corrêa and E. R. C. da Silva. "Sistemas de acionamento de dois motores de indução com número reduzido de componentes". Eletrônica de Potência - SOBRAEP, 10:67-76, 2005.

[4] E. C. dos Santos Jr, C. B. Jacobina, M. B. R. Corrêa, E. R. C. da Silva, A. C. Oliveira and E. B. de Souza Fl. "Control of ac motor drive systems without boost inductor", in Proc. of INDUSCON, pp. 309-320, 2004.

[5] C. B. Jacobina, E. C. dos Santos Jr, M. B. R. Correa and E. R. C. da Silva. "Ac motor drives with a reduced number of switches and boost inductors", in Proc. of IEEE APEC, pp. 733-739, 2005.

[6] P. Enjeti, A. Rahman, and R. Jakkli. "Economic single phase to three phase converter topologies for fixed frequency output”, in Proc. of IEEE APEC, pp. 88-94, 1991.

[7] G.-T. Kim and T. A. Lipo. "Vsi-pwm rectifier/inverter system with a reduced switch count", in Conf. Rec. IEEE-IAS Annu. Meeting, pp. 2327-2332, 1995.

[8] C. B. Jacobina, O. I. da Silva, E. C. dos Santos Jr., A. M. N. Lima and I. S. de Freitas. "Ac drive systems using five-leg converter and series-connected machines”, in Proc. of IEEE PESC, pp. 2429-2435, 2005.

[9] C. B. Jacobina, O. I. da Silva, E. C. Santos Jr and A. M. N. Lima. "Dual ac drives with five-leg converter", in Proc. of IEEE PESC, pp. 1800-1806, 2005.

[10] C. B. Jacobina, E. C. Santos Jr, M. B. R. Correa and E. R. C. da Silva. "Reduced switch count ac-ac two-phase drive systems", in Proc. of IEEE PESC, pp. 687-693, 2005.

[11] C. B. Jacobina, E. C. Santos Jr, and M. B. R. Correa. "Single-phase to three-phase-four-wire ac-ac component minimized converters without capacitor dc-bus midpoint connection", in Proc. of IEEE PESC, pp. 24152421, 2005.

[12] C. B. Jacobina, E. C. Santos Jr, M. B. R. Correa and E. R. C. da Silva. "Single-phase input reduced switch count ac-ac drive systems", in Conf. Rec. IEEE-IAS Annu. Meeting, pp. 2505-2511, 2005.

[13]E. Levi, M. Jones, S. N. Vukosavic and H. A. Toliyat. "A novel concept of a multiphase, multi-motor vector controlled drive system supplied from a single voltage ource inverter", IEEE Trans. Power Electron., 19(2):320-335, March 2004.

[14] E. Levi, M. Jones, S. N. Vukosavic, and H. A. Toliyat. "Operating principles of a novel multiphase multimotor 
vector-controlled drive”, IEEE Trans. Energy Conv., 19(3):508-516, Sept. 2004.

[15] M. Jones, E. Levi, and A. Iqbal. “A five-phase series connected two-motor drive with current control in the rotating reference frame”, in Proc. of IEEE PESC, pp. 3278-3284, 2004.

[16] G. Su and J. S. Hsu. "An integrated traction and compressor drive system for ev/hev applications", in Proc. of IEEE APEC, 2005.

[17] G. Su and J. Hsu. "A five-leg inverter for driving a traction motor and a compressor motor", in Proc. IEEE APEC, pp. 117-123, 2004.

[18] C. B. Jacobina, M. B. R. Correa, T. M. Oliveira, A. M. N. Lima and E. R. C. da Silva. "Current control of unbalanced electrical systems”, in Conf. Rec. IEEE-IAS Annu. Meeting, pp. 1011-1017, 1999.

[19] H. A. Toliyat, T. A. Lipo and J. C. "White. Analysis of a concentrated winding induction machine for adjustable speed drive applications. I. Motor analysis”, IEEE Trans. Energy Conv., 6(4):679-683, Dec. 1991.

[20] H. A. Toliyat, T. A. Lipo and J. C. White. "Analysis of a concentrated winding induction machine for adjustable speed drive applications. II. Motor design and performance”, IEEE Trans. Energy Conv., 6(4):684-692, Dec. 1991.

[21] M. B. R. Correa, C. B. Jacobina, E. R. C. da Silva and A. M. N. Lima, “A general pwm strategy for four-switch three-phase inverters”, IEEE Trans. on Power Electron., 21(6) :1618-1627, Nov. 2006.

[22] C. C. de Azevedo, R. L. A. Ribeiro, C. B. Jacobina, A. M. N. Lima, Fl. Braga and T. M. Oliveira. "Elimination the common-mode voltage in AC drive systems using a four-phase machine”, in Conf. Rec. IEEE-IAS Annu. Meeting, pp. 859-866, 2001.

[23] C. B. Jacobina, C. C. de Azevedo and A. M. N. Lima. "On-line estimation of the stator resistance and leakage inductance of a four-phase induction machine drive”, in Proc. IEEE PESC, pp. 1955-1959, 2002.

[24] C. B. Jacobina, M. B. R. Correa, C. R. da Silva, T. M. Oliveira, I. S. Freitas and E. R. C. da Silva. "Reduced switch count multiple phase AC motor drive systems without boost inductor filter", in Proc. of IEEE PESC, pp. 3390-3396, 2004.

\section{BIOGRAPHIES}

Euzeli Cipriano dos Santos Júnior, was born in Picuí, Paraíba, Brazil, in 1979. He received the B.S. and M.S. degrees in electrical engineering from Federal University of Campina Grande, Brazil, in 2004 and 2005, respectively, where he is currently pursuing the Ph.D. degree. In 2006, he is with EMPE - Electric Machines \& Power Electronics Laboratory, Texas A\&M University, Texas, USA, as a Research Scholar. Since August 2006, he has also been with the Centro Federal de Educação Tecnológica da Paraíba UNED Cajazeiras, Brazil. His research interests include power electronics and electrical drives.
Cursino Brandão Jacobina, was born in Correntes, Pernambuco, Brazil, in 1955. He received the B.S. degree in electrical engineering from Federal University of Paraíba, Campina Grande, Brazil, in 1978 and the Diplôme d'Etudes Approfondies and the Ph.D. degrees from Institut National Polytechnique de Toulouse, Toulouse, France, in 1980 and 1983, respectively. From 1978 to 2002, he has been with the Electrical Engineering Department, Federal University of Paraíba. Since 2002 he is Professor of electrical engineering in the Federal University of Campina Grande, Brazil. His research interests include electrical drives, power electronics, control systems, and system identification.

Maurício Beltrão de Rossiter Correa, was born in Maceió, in 1973. He received the B.S., M.S., and Ph.D. degrees in electrical engineering from Federal University of Paraíba, Campina Grande, Brazil, in 1996, 1997, and 2002, respectively. From 1997 to June 2004, he was with the Centro Federal de Educação Tecnológica de Alagoas UNED/PI, Palmeira dos Indios, Brazil. From 2001 and 2002, he was with WEMPEC, University of Wisconsin, Madison, as Scholar. Since July 2004, he has been with the Electrical Engineering Departament, Federal University of Campina Grande, Campina Grande, Brazil, where he is currently an Associate Professor of electrical engineering. His research interests include electrical drives, power electronics, and renewable energy. 